\title{
PUBLIC SPACES FOR SUSTAINABILITY OF CONTEMPORARY METROPOLISES: PROJECT THEMES AND RECURRING CHARACTERS FOR THE QUALITY OF DESIGN
}

\author{
GIUSEPPE CALDAROLA \\ Department of Architecture and Arts, IUAV University of Venice, Italy
}

\begin{abstract}
The present study records recurrent guidelines through different case studies of architectural and urban design projects, considered as "models" of different ways for managing the existing urban conditions due to generate new urban qualities. Innovative public spaces, new urban functions, formal/informal hybrid forms of living/using the city (or its parts) can be considered as "common" design topics of various interventions. Resetting urban fabrics, redesigning places, recharging their characters and values can be considered as starting points, shared tools of different regeneration projects, with strong strategical values and figurative features, especially in European and extra-European contexts: a "common ground" by which several contemporary metropolises are undertaking innovative policies and design features to rethink their existing conditions. In several cases - even with situational differences - enhancing the system of public spaces becomes an opportunity to improve their liveability. The "Laboratori Metropolitani" program of the IUAV University of Venice focuses on some contemporary metropolises, defines case studies, and allows the combination of research features and project actions due to recognizing and evaluating recurrent themes in these transformation dynamics. Different cities - such as Sao Paulo, Dar es Salaam, Seoul, New York, Santiago de Chile, Hong Kong, Mexico City and Moscow - have undertaken recent actions of urban regeneration. Recurrent ways of interventions are emerging, mostly public initiatives: virtuous processes of urban regeneration descend with significant effects in terms of urban quality. More complex urban regeneration policies can be appreciated, with positive effects on the same places and the surrounding areas, also consolidating and enhancing the specific identity matrices; different projects, supported by public policies and favored by different practices, follow the general principle/aimed output of qualification/implementation of the public realm (in its different forms). The interventions on the public spaces seem to be the main opportunity to create lasting condition of urban sustainability and inclusiveness, to generate liveable places.
\end{abstract}

Keywords: public space, collective realm, regeneration projects, urban design, quality of design.

\section{INTRODUCTION}

Several new processes of urbanization (or better, of re-urbanization) are overpassing contemporary metropolises, especially in extra-national contexts (European and more over extra-European): cities are expanding their dimensions; at the same time and more frequently, entire internal parts are under transformation (Jacobs [1]). Working in between the existing urban fabrics, high impact interventions are rethinking and redesigning the built city "per parts": new policies and new design processes are developed and activated due to transform places, change their character, increase their value (Aymonino et al. [2]).

In particular conditions of urban complexity - as imageable in the biggest world contemporary metropolises - various plans and programs are under activation. Various interventions have recurring characters: common design topics can be identified and can be reconducted under the public spaces system formation, renovation and development issues. Contemporary metropolises are trying to systematize the internal public spaces capacities to trigger positive transformation dynamics on larger portions of their urban fabrics. Managing 
the system of existing public spaces and increasing themselves, with their different levels of variations and integrations with the rest of the built city, seem to be a common denominator and, likewise, the main vehicle for transforming and implementing urban qualities, living qualities (Gehl [3], [4]).

\section{CONTEMPORARY METROPOLISES AND RECURRING DESIGN TOPICS: TRANSFORMING CITIES, MANAGING COMPLEXITY}

Some of the principal contemporary metropolises - different from each other and, as well as, in equally different contexts - have undertaken alternative actions of urban regeneration, both supported or triggered by innovative public policies and/or more spontaneous practices. In the same contexts, a lot of different projects can be checked as directly descending from the same policies and practices. Several projects deal with spaces of different natures, conditions and configurations. These cities have undertaken urban renovation projects which follow the more general principle/objective of qualification-implementation of the public space; they pass through gradual densification and redevelopment processes of more or less central areas, characterized by conditions of abandonment or degraded and affected by physical and social marginalization phenomena (Koolhaas [5]). For all these areas, alternative strategic actions are experimenting possible new urban condition scenarios and new life cycles assessments: through these, cities become a primarily relevant experimental laboratory (Caldarola [6]). The observation of the subsequent transformation dynamics that are affecting some of the world's major metropolises and megacities becomes a useful tool to set comparative views and analysis.

Specific dimensional parameters - as size, variety of transformations, strong physicalspatial and social inequalities - in some of the worldwide metropolises return not (at least not directly) comparable conditions with the largest part of the European cities: first differences can be recognized through the actual numbers of inhabitants and tendential population growth data, as well as, through the density data. The internal complexity conditions make almost impossible to imagine the formation of general plans and instruments capable of fully controlling and managing the whole transformations as a whole as well to form systemic projects, favoring designs made "per parts" (Caldarola [6]).

In these cities, principal questions concern old and new areas of expansion, new infrastructures and services which allow metropolitan territories, already in overcrowding of population, to reach new urban controlled volumetric densities and fluxus scenarios (Berghauser Pont and Haupt [7]). Investigating contemporary metropolises cases also allows to deal and measure with recurring conditions - even with differences by specific contextual conditions - which have already required the experimentation of innovative tools, capable of facilitating conceptions, promotions, managements and controls of the transformations.

Even in different geographical contexts and in equally different numerical-dimensional conditions and data - both from the increasing quantities of inhabitants to urban densities, spatial qualities and equipment of services and infrastructures - a sort of "common ground" seems possible to outline trough the different recent transformation processes. Various expansion processes, such as (and above all) those on internal still urbanized areas, concern dimensionally comparable surfaces; establish recurring calibres of interventions, types of interventions, types of spaces and functions (Sim [8]).

Alternative possible ways of implementing urban transformations, places for regeneration projects concentration, types of projects to be developed, actions to be undertaken, scenarios of new urbanity to be pursued are already under redefinition. In metropolitan contexts, have already emerged conditions of a sort of public action "surrendering" in the urban transformations management and control. Likewise, a sort of "rediscovery" and reactivation 
in the same public action is recognizable through promoting urban projects (their role becomes newly central): they become a new possible way to recover the effectiveness of promotion, control and government of transformations (Caldarola [9]).

Experimenting alternative strategic actions, urban projects are entrusted by the task of imagining new life cycles for more or less large parts of the cities, also for those parts not directly affected by the transformations but indirectly modified by them in their own characters, uses and possible users. By this newly central dimension, the urban project in itself is becoming the opportunity for new cycles of public actions and is allowing cities to become a laboratory where dealing with "unconventional" interferences between different and constantly evolving disciplinary areas.

In the same contexts, urban projects are proposed following several plans and programs, also conveying design competitions; new urban projects concern spaces of different natures and configurations; even if with different contextual variations, they descend from the more general principle/objective of qualification-implementation of the public space; they pass through imagining new life cycles for service infrastructures and promoting gradual and modulated processes of densification and redevelopment of more or less central areas of the cities, characterized by conditions of abandonment or degradation and/or affected by physical and social marginalization phenomena (Koolhaas [5]).

Through different projects and also through reconciling aspects related to the temporary nature of the interventions or to the experimental nature and to the communicative value of the same, the urban public spaces provision can be modified and expanded. Local problems are solved (often on a not larger scale than the neighborhood one), acting on the urban environment and developing various public policies. In particular, new public spaces are also generated by new involvements of citizens during the entire design processes, by increased usages of temporary and low-cost interventions (recurring to them especially in initial and preliminary stages of transformations). Small-scale interventions are increasing their numbers: they allow to trig virtuous regeneration dynamics on areas with greater surfaces than those directly under transformation and to support effective long-term results (such as numerous practices commonly indicated as situational or tactical ones) (Lyndon and Garcia [10], Paans and Pasel [11]).

The research of the IUAV University of Venice, made by the "Laboratori Metropolitani" program, analyzes some contemporary metropolises and allows to combine research and project actions due to record recurring transformations dynamics. A complex set of actions is emerging, mostly public and spontaneous ones, from which virtuous processes of urban regeneration descend. To deal with this topic, the research records the general guidelines of plans and programs and the projects they descend; the didactic programs - especially, the ones of the seminar "Laboratori Metropolitani" - try to accompany the same institutional actions with free design proposals, settled with the contribution of students in architecture. The analysis and design exercises allow to outline recurring methodological conditions and common actions between different urban contexts, also through the recovery and the innovation of integrated, multidisciplinary and multisectoral approaches in a multi-scalar vision, identified a useful tool for approaching specific urban conditions.

By comparing the results of the case analyses, has emerged the idea that the future structure of cities interested by strong demographic and economic expansions must start from a new look "from within", precisely from those "central peripheries" that represent the more problematic and alive part of the urban fabrics. Density, as a merely numerical or percentage data, seems no longer an insurmountable logistical problem: it becomes the starting point of unexpressed qualitative potentials if enrolled in reversing bad uses and consequent malfunctions of the involved quantities (Uytenhaak [12]). Precisely the unresolved or 
malfunctioning internal urban areas, due to their positions, visibilities, quantities of transits and connective potentials, have the ability to trigger virtuous processes, to expand models and meanings beyond their real dimensions, to produce exportable conditions, with appropriate measures and variations, on larger parts of the metropolitan areas.

\section{REARMING PUBLIC SPACES, REDEFINING PUBLIC REALM}

The project themes, on which the main internal transformations of contemporary metropolises are established, concern abandoned or partially dismissed areas, with lacks or their original functions or characterized by under-utilization or spontaneous high-density levels, often narrowed between infrastructural bundles and with incongruous scalar presences compared to pre-existing urban fabrics and road networks. They deal with those spaces commonly defined as "Neglected spaces", "Lost spaces", "24 hour spaces", "Invaded spaces", "exclusionary spaces", "Consumption spaces", "Privatized spaces", just to mention some possible categorizations traceable in various studies and research (Koolhaas [5]). Their recycle and reuse projects, undertaken as a possibility of new uses and lives chapters, are superimposing a sort of "lingua franca" in urban planning and urban design, also investing the architectural design projects (Marini and Corbellini [13]). Recent policies and projects take into increasingly account the reorganization of the sense of the possible ways of using the areas, especially conforming the public spaces, set as the backbone of new spatial and social configurations in contemporary cities.

These general ideas emerged working on the metropolises cases analyzed by the "Laboratori Metropolitani” program: São Paulo, Dar es Salaam, Seoul, New York, Santiago de Chile, Hong Kong and Mexico City, Moscow and Nanjing can be used as cases of cities (rapidly become metropolises or megalopolises in more or less recent times) interested by rapid dynamics of transformation, apparently different from each other but equally comparable, with common and recurring conditions of urban growth and transformations of internal areas, with high values of demographic increase and with significant modulation/remodulation of the existing fabrics and of the settled functions.

In these cities, new public policies of urban regeneration are under activation with topdown approaches; new spontaneous practices of appropriation (or reappropriation) and reuse of different places are emerging by bottom-up approaches and initiatives; huge renovation areas have been still transformed or are going to be identified as "resources", "starting point" for more complex developments; this, especially for achieving the more general objective of making the cities in themselves more liveable and sustainable.

These cities are re-compounding and recollect, in all design processes, the ways of living and using places issues or are exploring alternative possibilities to establishing different conditions trough alternative scenarios developments (Schenk [14]). Cities are reflecting on the spaces under transformation in themselves, on their specific conditions as on dimensional terms, characteristics and constitutional elements. Cities are working on the existing buildings, on more or less extended portions of the urban fabrics, trying to identify and avoid (or, at least, minimize) the impacts of all those elements that can act as barriers, limits, precincts: this, to generate new urban conditions of continuity and connection in those places, actually characterized by discontinuity, physical and social marginalization, improper uses, etc (Berghauser Pont and Haupt [7]).

Recurring topics can be identified through different projects, commonly indicated as good practices. Dealing with the establishment of new densities - which usually are modulated and allowed to support the transformation costs - cities are forming new plazas, boulevards and green areas due to increase the quantities of places for staying, for gathering (Gehl and Svarre [15]). These kind of interventions are settled to change the character of places, only 
addictable as transitional ones. Cities are forming a revitalized network of streets and covered and open air passages due make more recognizable their capability of being places suitable for the open air living (Colville-Andersen [16], Sadik-Kahn and Solomonow [17]). Cities are managing the public transport and are improving the cycle and pedestrian accessibility to their inner areas. For all the regeneration areas, a new integrated program of materials an urban furniture is defined to enhance their recognisability. Cities are making themselves "greener"; are texting alternative ways to generate 24 hour spaces or to obtain a maximized extension of the using times due to avoid risks connected to low using levels (mixed uses for mixed users, also increasing the role of young population).

The compresence of these topics and their specific uses, allows the creation of liveable and suitable places and, as the same, act as an indicator of the quality of design. These topics - with alternative specific weights per each design process - follow the general objective of rearming the urban public spaces system, of enhancing its own capability in giving specific characters and identities to the place which belong and to the city in itself (or, at least, to a significant part of it) (Stipa [18]).

\section{A BRIEF REVIEW ON CASE STUDIES: \\ PROJECTS FOR CITIES "FULL OF SPACE"}

Gradual densification dynamics are interesting the city of São Paulo. Entire parts of its urban fabric are under transformation by several different kinds of interventions: especially at the neighborhood scale, the city is redesigning existing grids, road networks and plots by replacing existing buildings, in-filling services, varying densities, creating or managing the existing open air spaces quantities. Common topic of this interventions is to experiment possible changes in users and uses of the same public spaces under transformation and their possible functions. The overall image of these transforming places and their original vocations are changed; new urban population groups are installed. These dynamics of transformations do not respond to general planning but to partial logics, more often induced by the real estate market, determining the creation of friction areas, residual spaces and process waste. Along their borders, informal settlements are forming or reforming with unequal socio-economic conditions in occupying and neighboring the same urban sectors. Extremely different housing models are placing in direct comparison, alternating seamlessly throughout the territory. Physical proximity and social distance generate a mapping of heterogeneous isolated fences within the same urban sectors, held together only by the infrastructural networks, of which the transformation and/or adaptation to the new residential pressure is not often expected.

Dar es Salaam is registering rapid expansion of urbanized territories with population growth data that foresee the doubling of the current 4,000,000 inhabitants (registered) over a decade. Settlement pressure, as a consequence of short-range migratory flows, feeds the informal settlements sectors increasing, characterized by low quality housing, lack of infrastructure and diffuse self-construction. Recent public policies aimed to realize minimal services to reach a general improved (as possible) conditions of quality living in informal settlements: these policies have produced poorly structuring results, at least not systemic or capable of generating a new overall image of the places.

Interventions limited on individual lots or urban blocks can be checked, not deriving from a general planning program but resulting and depending from economic interest of the real estate market or of the private investments. As general results of this condition, several different areas of friction and residuals spaces are emerging and the image of a city without "architecture" is superimposing: the one of a city, composed by heterogeneous fabrics, belonging to the different phases of urban growth and alternatively attributable to "planned" 
interventions or self-construction. Through a new general urban plan (2012), the city is responding to settlement pressure, to the demand for areas for residential and non-residential settlements, to the necessary improvement of living conditions in informal settlements. The new Masterplan provides the redesign of core areas superimposing a grid of spatial units, in which urban questions would be solved at a neighborhood scale, and the formation of five new satellite cities. Contemporarily, the plan promotes the containment of the expansion of built-up areas by the activation of modulated densification processes or reassessments of portions of the existing urban fabrics.

Existing infrastructure networks, public transport systems, neighborhood services are under transformation and reorganization; new urban micro-centralities and areas of protection and enhancement of naturalistic and environmental emergencies are under creation; landscape protection and specific measures to prevent hydrogeological instability on flooding areas are under promotion, also with the introduction of forms of urban agriculture. For specific conditions of urbanity and complexity, Dar Es Salaam becomes a laboratory for experimenting alternative life cycles for the public spaces aimed at implementing the quality of living (Bartolone and Caldarola [19]).

Seoul returns dynamics of rapid population growth with strong settlement pressure, spatially defined by expansion and regeneration areas, introduction of new modulated densities. Through several urban regeneration interventions, significant central parts of the city had already been re-established by the creation of new public services and equipment as well as by the more general requalification and implementation of public spaces systems, also accompanied by the transformation of the urban infrastructures. Plans and programs had already guided public actions and private initiatives - these one, especially supported by a series of interventions promoted by the principal industrial corporations - and have supported high-density residential constructions interventions. The masterplan for Cheonggyecheon area could be considered as an emblematic case of urban regeneration: the regeneration of that central part of the city started from the transformation of the existing infrastructures and aimed at the formation of a new city center by enhancing the public spaces systems.

The public urban regeneration program had led to the reopening of the stream, the canal that had been covered to build up an urban highway after the war. The dismantling intervention of the urban highway, the reopening of the canal and the formation of the new linear public spaces for a total extension of $10.9 \mathrm{~km}$ was carried out in 2005. Starting from this construction, various neighboring areas has flourished with intensive building interventions by substitutions of the existing fabrics. Despite the extensive transformations already occurred - conveyed by the formation of the new linear public space - the Seoul municipality is trying to preserve some historical or modern buildings along the stream, as the Sewon Sangaa one: their preservation criteria are under definition and are submitted to the more general addresses of the debate on the formation of the new public spaces system along the stream and surrounding areas.

The Sewon Sangaa is a $1 \mathrm{~km}$ long building, located along the fire zone of the Japanese occupation period. It is a "manifesto" building with its specific architectural facies. It exemplifies recurring urbanization conditions, recognizable in several parts of the inner areas of the city, affected by significant urbanization or re-urbanization processes at the beginning of the second half of the 20th century. Those areas show recurring characteristics of juxtaposition and compresence of different functions within the same urban blocks or within the same building. Close to the Sewon Sangaa building there is an informal settlement, functionally dense and with main productive vocation: settled activities ranging from the electronic components to paper mills and ironworks sectors, with very high productivity indices such as to make the eight informal urban blocks (of which the building constitutes 
the central spine) a sort of "perfect machine" and almost unchangeable Here the real estate pressure would like the demolition of the macro-scale building that constitutes the backbone of the surrounding informal settlement to create a public park with mixed-use towers (mainly tertiary ), forming a new downtown. A first masterplan was made on private initiative, against which efforts were being made to define various strategic actions of public initiative, aimed at the conservation of the building (considered as an "heritage" building, a "manifesto" of the Korean economic boom), re-functionalising it and intervening punctually by infilling micro-scalar public equipment.

In New York, following new public policies (supported by the transportation and construction departments of the municipality), are allowing several interventions of urban regeneration: through these, the municipality aims to regenerate the existing city and to contain the more recent expansionary trends. A systematic series of interventions have affected the island of Manhattan, starting with the redevelopment of its riverfront following the dismantling of the port system along the entire perimeter with the formation of new urban parks and the location of new public facilities. Alongside these interventions, the redevelopment of existing public spaces and the reorganization of the road networks have started: main results of these policies can be easily recognizable through the interventions that have lead the reassessment of Times Square, transformed into a pedestrian areas starting from a space traffic dominated, and all along the Broadway 7 miles route.

Directly descending from these previous formal interventions, a systematic program of public and private interventions is interesting areas with main residential vocations in the neighborhoods of Queens, Brooklyn and the Bronx. Here, alongside interventions aimed at redesigning roadway reinforcement - made under the general principle of encouraging pedestrian uses of urban spaces and reorganizing the streetscape components - the formation of public micro-spaces, the networking of pedestrian paths and public spaces and the implementation of themselves are undertaken, also with compensation systems due to promote and encourage private initiatives (i.e., the BIDs programs) in the creation of neighborhood services and equipment.

The interventions carried out along Roosevelt Avenue, integrated with the formation of new neighborhood micro-equipment and public supports for private initiatives, make the areas of Queens a representative case of more general methods of interventions on urban public spaces and on the possibility of amplifying their uses and users also improving the integration of semi-public, semi-private and private areas.

The municipality of Santiago de Chile has recently implemented new urban regeneration policies. Among the numerous interventions that generated the modulation/remodulation of existing densities, particular attention has been given to the implementation of the urban public space system: both existing and newly formed ones whose program has been carefully examined by the municipality since from the start of the ideation of the transformation and in every phase of the approval procedures. Through international design competitions, the municipality intended to promote the drafting of masterplans that had significant effects in terms of the regeneration of the spaces inside the consolidated city.

The competition for the Alameda Avenue is one of one of the effective instruments descending from the new public policies, also and above all for the central role of the areas included in the design proposals. The Alameda is the road axis that crosses the entire city on the east-west direction, really close to the original terrain of the Rio Mapocho, the river that was buried to make space for the creation of an urban highway and recently affected by the reopening and by conspicuous interventions of building speculation along its course. Alongside the Alameda, the municipality is promoting systematic actions aimed at the 
formation of sequences of ringed public spaces, also and above all starting from the infrastructural reorganization.

Mexico City shows complex and alternative urban conditions, comparable to the other cases in terms of quantities and qualities of numbers of inhabitants, population, areas under transformation, public policies and private initiatives with more or less significative effects on the urban fabrics. Particularly significant of the ongoing debate on the transformability of the city, on urban regeneration topics, on buildings and urban transformations in progress is what is now under construction along the extension of the Ferrocarril de Cuernavaca. This is the area of a local the railway track, partially dismissed and characterized by low levels of usage, that crosses eleven neighborhoods, significantly different in terms of social composition and conditions of urbanity. Along the railway road a linear park (the "Bosque urbano Ferrocarril de Cuernavaca" project, made under public promotion by the GaetaSpringall Office) is reopening to the city an infrastructural space, till now privatized and affected by spontaneous and uncontrolled different uses by the citizens. Mixing design processes with direct participative programs for the population, the formation of the linear public space Bosque Urbano FLCC, alongside the infrastructure, is becoming the principal occasion to develop a urban quality project in Mexico city.

\section{TOWARD NEW URBAN CONDITIONS: THE "COLLECTIVE SPACE” CHANCE}

In all the case studies, urban policies and design actions highlight recurring conditioned in terms of transforming surfaces dimensions, specific characteristics, varied design "calibers" grafted onto them, types of the descending interventions. Always central are the topic of qualifying and implementing the system of urban public spaces; forming "networks" of spaces through the implementation of connective systems between green areas, traffic calmed areas and pedestrian ones and between different public transport systems. Equally central are the needs of multidisciplinary and interdisciplinary approaches to urban issues, for new possible integrations and interactions between specialized knowledges (White [20]). Transforming the role and character of urban infrastructures becomes an opportunity to redevelop parts of the cities in which they fall; new centralities can be generated working on unresolved urban passages, poised between abandonments and improper uses, characterized by "exclusionary" conditions, inaccessible and detached from their closest contexts or characterized by low levels of integration. In each metropolitan case, new public spaces derive from new ways of dealing with the relationships between cities and their infrastructures, city centers and their peripheries, formal areas and informal ones, planned and self-constructed areas, vertical and horizontal dimensions, fences or borders and margins.

In all these addressed cases, specific analyses have been conducted on areas included among infrastructural bundles for checking modalities by which these modulated relationships could become occasions of increased urban quality and for establishing higher integration conditions with the external fabrics and with the surrounding buildings (i.e., the dismissed or characterized by conditions of underutilization railway tracks of São Paulo and Mexico City); on the systems of spaces more or less directly connected with road axes for which alternate scenarios of configurations of networks of public spaces are imagined (i.e., the Alameda Avenue of Santiago de Chile or the Roosevelt Avenue of New York); on more or less significant parts of urban fabrics characterized by absence or scarce supply of public services and equipment (i.e., the Sewon Sangaa area of Seoul, the residential areas of Queens along Roosevelt Avenue in New York or the informal and planned settlements of Dar es Salaam); on relationships between macro scalar presences and inconsistencies in different urban fabrics for which different configurations are hypothesized (i.e., the Sewon Sangaa of 
Seoul and the neighboring fabric); on the new settlements and the methods of generating quality of living, also and above all, according to criteria of containment of soil consumption and of self-sufficiency and sustainability.

The case studies show different possibilities to generate new urban public spaces systems starting from the renovation of the existing ones or from the creation of new, often "unconventional", ones that can flourish alongside, amongst, within or in-between the consolidated urban fabrics.

The creation of a new public space becomes an "occasion" to improve urban quality, to make cities (or significant parts of them) more liveable and sustainable, only if the specific conditions settled by the projects pass through a complete evaluation of the possible outcomes on the enhanced public realm. Proper the appertaining of the newly generated system of public spaces to the public realm - this last, as in its own more general accepting of "Place for people" - becomes immediately recognizable if it clearly shows its specific conditions of being accessible and inviting, lively and diverse, healthy and prosperous, attractive, safe and secure (and this, joining both the physical and spatial settings and the perceptive components) (Gehl [3]).

These features seem to be the core issues of the quality of design, to be considered, declined and compounded to enhance projects values.

Successfully places outcome from not just realizing a public space but compounding itself as an enhanced part of the public realm; successfully projects flourish considering each intervention of urban regeneration as a chance to improve the collective space, the indicator of the health status of the urban public realm (Sennett [21]).

Qualities of design could emerge if the increasing the public spaces system topic maintain a central role in whole design processes. They could reach full values if the same design processes are informed on: multidisciplinary approaches, to allow the possibilities of retraining specialistic or sectorial projects in the main topic of the development of the quality of the "public" city; new densities, to increase different possible uses and users; mixed uses and social values completion, to form places for staying with rebalanced conditions of transition between public and private realms; networking, to overcome the condition of a public realm made per punctual spaces, not connected, and to favourite interconnected systems of public spaces and public services; permeability, to reset exclusionary condition; calibres of interventions, to generate significative impacts overcoming the specific perimeters and dimensions of the transforming areas and to reopen the project areas to their context; balanced condition of low design and high impacts features and of low costs and high tech components, to reopen the areas to the possibilities of generating unconventional and unexpected uses, retain attractiveness, environmental liveability, reversibility and successive completions of the interventions.

\section{ACKNOWLEDGEMENTS}

This paper is based on the research results of the "Laboratori Metropolitani" program which is coordinated by the author join with the architect Roberta Bartolone. Laboratori Metropolitani is a 4 year research and teaching program opened to Italian universities students in architecture participating in the network of the Villard de Honnecourt seminar, established by the IUAV University of Venice jointly with several foreign universities. The Lab. Met. program was activated with the aim of developing research on issues relating to the implementation of sustainable development models for selected contemporary metropolises cases, characterized by strong expansion and/or transformation dynamics. The scientific committee is composed by professors Aldo Aymonino, Enrico Fontanari, Paolo Bonvini, Gianluigi Mondaini, Rita Simone and other professors and researchers of the 
foreign universities to whom special thanks by the author of this paper have to be addressed for their contribution of ideas. The first edition of the program took place in São Paulo, Brazil, with the Universidade de São Paulo (USP) - Faculdade de Arquitetura e Urbanismo (2011); the second in Dar es Salaam, Tanzania, with the Ardhi University of Dar es Salaam (2012); the third in Seoul, Korea, with the SKKU University of Seoul (2013); the fourth in New York with the Parsons New School of Design (2014); the fifth in Santiago, Chile, with the Universidad Diego Portales (2015); the sixth in Hong Kong with the Polytechnic University of Hong Kong (2016); the seventh in Mexico City with the Ibero-American University (2017); the eighth in Moscow with the Moscow Institute for Architecture (2018); the ninth in Nanjing with the Southeast University of Nanjing (2019). In each edition, the case studies and project areas are proposed by the host foreign university on the basis of a common thematic and interpretative grid. The laboratory, with annual programming, is structured in a cycle of introductory lessons, a study trip with on-site surveys and 2 week workshops plus an 8 week intensive workshop in Venice during which the first analyses and design ideas, as emerged during the workshop abroad, are deepened, completed and reassessed in a final exhibition and in a seminar.

\section{REFERENCES}

[1] Jacobs, J., Vita e morte delle grandi città, Italian ed., Einaudi, 2009.

[2] Aymonino, A., Bartolone, R. \& Caldarola, G., Laboratori metropolitani Riciclare città. Esercizi di postproduzione, ed. S. Marini, Quaderni della ricerca del Dipartimento di Culture del Progetto - Iuav, Aracne ed., Rome, pp. 90-109, 2014.

[3] Gehl, J., Cities for People, Island Press, 2010.

[4] Gehl, J., Life Between Buildings: Using Public Space, Island Press, 2011.

[5] Koolhaas, R., Junkspace. Per un ripensamento radicale dello spazio urbano, Quodlibet, 2006.

[6] Caldarola, G., Metropoli come laboratorio: da piani, programmi e progetti a esperienze di didattica e ricerca. Proceedings of the XXI Annual SIU Conference, Confini, movimenti, luoghi. Politiche e progetti per città e territori in transizione, 2019.

[7] Berghauser Pont, M.Y. \& Haupt, P.A., Spacemate: The Spatial Logic of Urban Density, Delft University Press Science: Delft, 2002.

[8] Sim, D., Soft City: Building Density for Everyday Life, Island Press, 2019.

[9] Caldarola, G., Metropoli come laboratorio: da piani, programmi e progetti costruiti a esperienze di ricerca e didattica. Urbanistica Informazioni, 278, INU edizioni, 2019.

[10] Lyndon, M. \& Garcia, A., Tactical Urbanism. Short-Term Action for Long-Term Change, 3rd ed., Island Press, 2015.

[11] Paans, O. \& Pasel, R., Situational Urbanism: Directing Postwar Urbanity. An Adaptive Methodology for Urban Transformation, Jovis, 2014.

[12] Uytenhaak, R., Cities Full of Space: Qualities of Density, 010 Publishers: Rotterdam, 2008.

[13] Marini, S. \& Corbellini, G., Recycled Theory: Dizionario Illustrato/Illustrated Dictionary, Quodlibet, 2016.

[14] Schenk, L., Designing Cities: Basics, Principles, Projects, Birkhäuser: Basel, 2013.

[15] Gehl, J. \& Svarre, B., How to Study Public Life, Island Press, 2013.

[16] Colville-Andersen, M., Copenhagenize: The Definitive Guide to Global Bicycle Urbanism, Island Press, 2018.

[17] Sadik-Khan, J. \& Solomonow S., Streetfight: Handbook for Urban Revolution, Penguin: USA, 2017. 
[18] Stipa, A., Il disegno urbano nasce dalla densità di funzioni, significati e potenzialità. Controspazio, 2, pp. 46-63, 1994.

[19] Bartolone, R. \& Caldarola, G., Dar es Salaam, paesaggi urbani per la qualità dell'abitare. Infrastrutturare l'informale, pianificare lo sviluppo. La freccia del tempo. Ricerche e progetti di architettura delle infrastrutture, eds C. Cozza \& I. Valente, Pearson: Milan and Torino, pp. 280-283, 2014.

[20] White, W.H., The Social Life of Small Urban Spaces, Project for Public Spaces Inc., 1980.

[21] Sennett, R., Costruire e abitare. Etica per la città, Feltrinelli, 2018. 